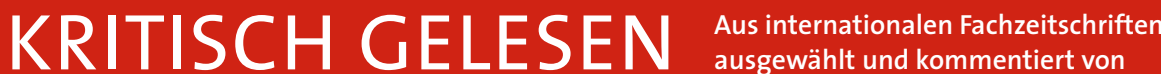

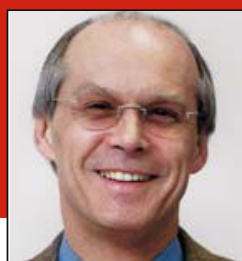

Prof. Dr. med. H. S. Füeß| Isar-AmperKlinikum, $\mathrm{KI}$. MünchenOst, Haar

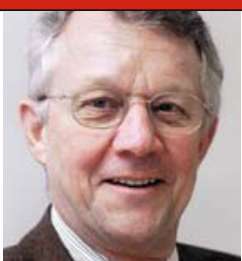

Prof. Dr. med. H. Holzgreve Internist, Kardiologische Praxis, München

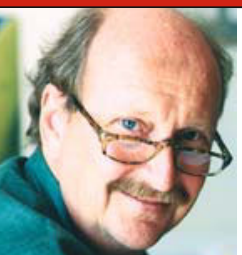

Prof. Dr. med. E. Ernst

Peninsular Medical School, University of Exeter/UK

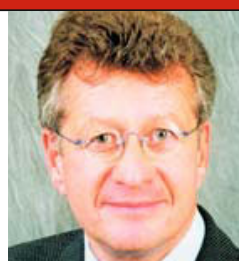

Dr. med. P. Stiefelhagen

Westerwald Krankenhaus, Hachenburg

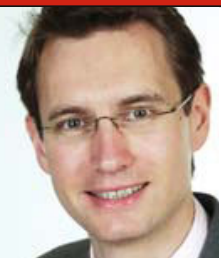

Prof. Dr. med. G. Rohde

Universität Maastricht

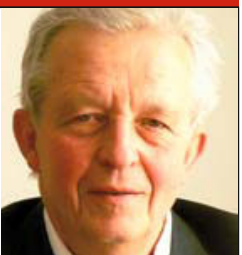

Prof. Dr. med. K. Malberg Immunologie, DresdenLoschwitz

\section{Anwendung von Defis durch Laien rettet Leben}

Wenn Defibrillatoren in der Öffentlichkeit aufgestellt werden und ihre Zahl erhöht wird, verbessern sich die Überlebenschancen für Patienten mit akutem Herzkreislaufstillstand.

— Die Ergebnisse stützen sich auf eine prospektive Studie zwischen Januar 2005 und Dezember 2007 in Japan. In diesen drei Jahren wurden 55271 Herzkreislaufstillstände von Umstehenden beobachtet und bei 12631 ein Kammerflimmern festgestellt. Den ersten Elektroschock erhielten 462 Patienten mit einem öffentlichen Defibrillator durch Umstehende und 11697 durch ein Notarztteam, während 472 ohne diese Behandlung blieben.
Die beiden wichtigsten Ergebnisse:

(1) Die Überlebensrate nach einem Monat ohne nennenswerte neurologische Spätfolgen betrug $31,6 \%$, wenn der erste Schock durch Umstehende mit öffentlichem Defibrillator erfolgte, aber nur 14,4\% bei einer Erstbehandlung durch das Notfallteam. Wenn der erste Schock durch Laien erfolgreich war, betrug die Erfolgsrate sogar 85\% (s. Tabelle 1).

2 Die Rate der Patienten mit Herzstillstand, die einen ersten Schock durch Umstehende mit einem öffentlichen Defibrillator erhielten (im Mittel $3,7 \%)$, stieg von $1,2 \%$ im Jahr 2005 über 3,2\% (2006) auf 6,2\% (2007), also um etwa das Fünffache an, während

\section{Tabelle 1}

\section{Überleben (\%) nach 1 Monat ohne nennenswerte neurologische Spätfolgen \\ Erster Schock}

Durch Umstehende

Durch Notarztteam

Zahl der Patienten

Überlebensrate

$462(3,7 \%) \quad 11697$

1. Schock durch Laien

erfolgreich

Weiterbehandlung durch

Notarztteam

Insgesamt
$462(3,7 \%)$

$71(85 \%)$

$75(19,8 \%)$

$146(31,6 \%)$ sich die Zeit zwischen Herzstillstand und erstem Schock von 3,7 auf 2,2 Minuten verkürzte. Dies geht parallel mit einer erhöhten Bereitstellung öffentlicher Defibrillatoren von 0,11 auf 0,97 pro/ $\mathrm{km}^{2}$ bewohnter Fläche.

$$
\text { Kommentar }
$$

Da plötzliche Herztodesfälle insgesamt selten sind (in einer Stadt wie München etwa fünf Ereignisse pro Tag), werden nur äußerst wenige den Defi selbst einmal anwenden. Doch dessen Nutzen bemisst sich nicht nach der Häufigkeit des Einsatzes, sondern nach dem eminenten Erfolg der schnellen Anwendung, die den Unterschied zwischen Tod und Leben ohne Langzeitfolgen ausmacht. Deshalb können nur bevölkerungsweite Erhebungen den Nutzen derartiger Präventivstrategien gegen den plötzlichen Herztod nachweisen. Da viele zusätzliche Faktoren wie Kenntnisse in der Wiederbelebung und zur Anwendung derartiger Geräte einschließlich der Bereitschaft zur Hilfeleistung in der Allgemeinbevölkerung den Erfolg bestimmen, wären entsprechende Untersuchungen auch in Deutschland wünschenswert.

H. HolzGreve

- T. Kitamura et al.

Nationwide public-access defibrillation in Japan. New Engl. J. Med. 362 (2010) 994-1004 